\title{
Why technology-based regulations don't work
}

\author{
Sue Mayer
}

The technology-based risk assessments of genetically manipulated organisms (GMOs) are not working. Industry is dissatisfied because the potential benefits of GMOs are not explicitly included and thinks undue emphasis is placed on the risks. Nongovernmental organizations (NGOs) are frustrated because their broader concerns about the role of GMOs in agriculture and whether GMOs are an appropriate technology, or needed at all, are excluded. Regulators and their advisers acknowledge the relevance of such questions, but feel that the pressure on them is inappropriate as such issues are perceived to be outside their scientific assessment. So no one is satisfied.

This dissatisfaction was clearly apparent at the seminars held by the Green Alliance and the Centre for the Study of Environmental Change (Lancaster University, Lancaster, UK) in Autumn 1995, which were attended by members of the UK's biotechnology industry, NGOs, regulators, and expert advisors.

The discontent expressed there is now reflected in fierce opposition from environmentalists and consumers to Monsanto's (St. Louis, MO) genetically engineered soybean. Industry is likely to face consumer boycotts because the regulations that supposedly ensure safety for everyone have the confidence of no one. The possibility of a trade war looms between the United States and Europe over Ciba-Geigy's (Basel) transgenic corn if Europe bans its import because of different interpretations of the risks. Clearly, the regulations aren't working.

Why are current regulations failing and so dislocated from the concerns of two important communities-industry and NGOs-and the cause of such disagreement between European Union (EU) member states? Are NGOs being irrational and antitechnology? Is industry simply uninterested in a serious assessment of potential harm? Are some countries not applying the regulations properly?

The EU's deliberate release directive, which covers the safe release of GMOs, only focuses on the immediate technical aspects of genetic manipulation, such as the vector, donor, and recipient organisms and how these influence the likelihood of harm. However, much of the data needed to make these decisions is uncertain or missing, so regulators

Sue Mayer is a consultant in environmental science and policy issues and an honorary research fellow at Lancaster University. She was formerly director of science at Greenpeace, UK. (sue.mayer@green2.greenpeace.org). and their advisors have to make value judgments, for example, about whether it matters if gene flow to native flora occurs. What consideration is given to how different agricultural practices affect risk? Denmark and Austria want consideration of genetically engineered, herbicide-resistant crops and their potential for changing patterns of herbicide use and encouraging resistant weed evolution to be part of the evaluation. The UK, in contrast, argues that this is a matter for other authori-

\section{Not acknowledging differ- ences between genetically engineered and traditionally bred crops is one of the systematic shortcomings of regulatory systems on both sides of the Atlantic.}

ties and draws a distinction between risks to the natural and agricultural environment. In making their judgments, all countries operate under a "taken-for-granted" assumption that genetic engineering is desirable, with differences only over the extent to which the effects matter and over who is responsible for them. This is more than just science, but making purely "scientific" decisions is what governments claim is happening.

For those, like the NGOs, with ethical concerns about genetic engineering or questions about the whole future path of agriculture, the case-by-case approach mitigates against any real impact. Their questions about alternatives and risk justification have little value when one crop with one gene alteration is discussed at a time. Yet the overall additive effect may materially affect risk. Genetically engineered glyphosate-resistant soybean may have a limited effect, but together with glyphosate-resistant sugar beet, oilseed, potatoes, and tomatoes, the final effect may far from limited, either in herbicide use, the evolution of resistant weeds, or in gene transfer. The progress of one Roundup Ready crop is inevitably linked to the progress of the others.

Not recognizing the validity of such concerns or acknowledging the significance of differences between genetically engineered and traditionally bred crops is one of the systematic shortcomings of regulatory systems on both sides of the Atlantic.
While industry places great emphasis on the benefits of GMOs, these are as contentious and uncertain as the risks. Although industry feels that the lack of appreciation of the benefits is a consequence of poor public understanding of the technology, this is not supported by the evidence. Concerns about the products of genetic engineering go beyond which gene is involved or what promises GMOs hold.

Is there a way forward or is continuing conflict inevitable? Seeing the problem, as industry and some government advisers do, as one of managing or engineering public acceptance, is not only deeply antidemocratic but courts disaster. If the public, like the NGOs, finds the boundaries of risk assessment unconvincing, this will pose continuing problems of justification. If regulators pass responsibility elsewhere when questioned about issues they perceive to be outside their domain, they will further contribute to the corrosion of public confidence in institutions and political systems. Saying that the market must determine need and benefit while denying consumers choice (as is happening with Monsanto's soybean) will be seen as favoring certain powerful interests.

One country that has recognized and tried to address problematic genetic engineering regulations is Norway. According to their Gene Technology Act, the use of GMOs must be undertaken in an ". . .ethically and socially justifiable way. .." and in deciding whether releases should be allowed ". . . significant emphasis shall also be placed on whether the deliberate release represents a benefit to the community and a contribution to sustainable development." Of course, explicitly including such statements does not make their implementation easy, but it does end the concealment of such judgments inside technology risk assessments.

Gathering intelligence about people's concerns and aspirations and making tighter links to our democratic processes are steps that need to be taken to improve decisions about the risks of GMOs. New participatory processes such as people's parliaments and public hearings that actually influence decisions must be explored. Industry may have to face some unpalatable rejections (for example, in November a lay panel concluded there is no need for genetically modified food in Norway), but it should make for better long-term, stable relationships with the public built on products that are wanted or needed. Regulators can only gain from more robust and agreed-upon decision-making processes. I/I 